TITLE:

\title{
Elimination of AsF3 from anhydrous HF using AgFAsF6 as a mediator
}

\author{
$\operatorname{AUTHOR}(S)$ :
}

Matsumoto, Kazuhiko; Hagiwara, Rika

\section{CITATION:}

Matsumoto, Kazuhiko ... [et al]. Elimination of AsF3 from anhydrous HF using AgFAsF6 as a mediator. Journal of Fluorine Chemistry 2010, 131(7): 805-808

ISSUE DATE:

2010-07

URL:

http://hdl.handle.net/2433/126622

\section{RIGHT:}

C 2010 Elsevier B.V.; この論文は出版社版でありません。引用の際には 出版社版をご確認ご利用ください。; This is not the published version. Please cite only the published version. 
Elimination of $\mathrm{AsF}_{3}$ from anhydrous HF using $\mathrm{AgFAsF}_{6}$ as a mediator ${ }^{\dagger}$

Kazuhiko Matsumoto*, Rika Hagiwara

Graduate School of Energy Science, Kyoto University, Sakyo-ku, Kyoto 606-8501, Japan,

*E-mail: k.matsumoto@ky7.ecs.kyoto-u.ac.jp

Tel: +81-75-753-5822

Fax: $+81-75-753-5906$

Key words: Arsenic, Hydrogen fluoride, Purification, Arsenic trifluoride

${ }^{\dagger}$ Dedicated to the late Professor Neil Bartlett in recognition of his many achievements in inorganic fluorine chemistry, including transition metal fluorides in high oxidation states. 


\begin{abstract}
Elimination of the arsenic (III) impurity $\mathrm{AsF}_{3}$ from anhydrous hydrogen fluoride has been demonstrated using a bench-scale apparatus $(\sim 500 \mathrm{~mL}$ of $\mathrm{HF})$, with a $\mathrm{Ag}(\mathrm{II})$ salt $\mathrm{AgFAsF}_{6}$ as a mediator. In this process, $\mathrm{AsF}_{3}$ is oxidized by $\mathrm{AgFAsF}_{6}$ to $\mathrm{AsF}_{5}$. In the next step, $\mathrm{AsF}_{5}$ is eliminated from $\mathrm{HF}$ by reaction with $\mathrm{NaF}$. The oxidizer, $\mathrm{AgFAsF}_{6}$, is reduced to $\mathrm{AgAsF}_{6}$ which is regenerated to $\mathrm{AgFAsF}_{6}$ by $\mathrm{F}_{2}$ in $\mathrm{HF}$ at room temperature. This method can reduce the arsenic content in HF from a few hundred ppm to the industrially-required level ( $<3 \mathrm{ppm})$. The results for three other methods (distillation, oxidation by $\mathrm{F}_{2}$ gas, and oxidation by $\mathrm{K}_{2} \mathrm{NiF}_{6}$ ) are reported and compared with the $\mathrm{AgFAsF}_{6}$ method in a preliminary examination (using $\sim 4 \mathrm{~mL}$ of $\mathrm{HF}$ ).
\end{abstract}




\section{Introduction}

Hydrogen fluoride is the precursor for many fluorine-containing materials and is also used as a fluorinating reagent or a solvent. Hydrogen fluoride is manufactured on a scale of millions of tons per year, mainly by the reaction of fluorite (also called fluorspar) and sulfuric acid, but resources of the high-quality fluorite required for industrial preparation are limited to certain areas, such as China. However, appropriate treatment may reduce impurities in the resulting HF, allowing lower-quality fluorite to be used.

The main impurities resulting from the reaction between fluorite and sulfuric acid such as $\mathrm{SiF}_{4}$ and $\mathrm{SO}_{2}$ are usually removed by fractional distillation. Impure fluorite can contain arsenic species with an oxidation state of three, which is much more difficult to remove from HF. This is because the $\mathrm{As}(\mathrm{III})$ species is converted in anhydrous $\mathrm{HF}$ to $\mathrm{AsF}_{3}$ which has similar physical and chemical properties to $\mathrm{HF}$ (e.g. boiling point: $19^{\circ} \mathrm{C}$ for $\mathrm{HF}$ and $57{ }^{\circ} \mathrm{C}$ for $\mathrm{AsF}_{3}$ ) [1,2]; in addition there is a possibility of interaction between $\mathrm{HF}$ and $\mathrm{AsF}_{3}$ molecules that may impede the separation by distillation. Several techniques have already patented for the removal of $\mathrm{AsF}_{3}$ from $\mathrm{HF}$ [3]. One plausible method would be oxidation of $\mathrm{As}(\mathrm{III})$ to $\mathrm{As}(\mathrm{V})$ using a strong oxidizer such as $\mathrm{F}_{2}$ or $\mathrm{H}_{2} \mathrm{O}_{2}$. The product $\mathrm{AsF}_{5}$, as opposed to $\mathrm{AsF}_{3}$, has completely different physical and chemical properties to those of $\mathrm{HF}$, so it can be more easily removed. However, slow reaction rate, oxidizing reagent recovery, and generation of industrial wastes remain problematic.

In this communication, a new oxidizing pathway for $\mathrm{As}(\mathrm{III})$ to $\mathrm{As}(\mathrm{V})$, using a silver complex salt 
$\mathrm{Ag}(\mathrm{II}) \mathrm{FAsF}_{6}$, is examined to allow effective removal of As impurity from HF. The target As content in HF was below 3 ppm, which represents a sufficient purity for industrial use. The starting As content was adjusted to a few hundred or thousand ppm to reflect HF synthesized from As-containing fluorite such as that produced in Mexico. The oxidizing salt, $\mathrm{AgFAsF}_{6}$, was first reported in 1982 [4], and was characterized by several methods [5-7]. The solid-state structure of $\mathrm{AgFAsF}_{6}$ contains a cationic $(\mathrm{Ag}-\mathrm{F})_{\mathrm{n}}$ chain, and an octahedral $\mathrm{AsF}_{6}$ group cross-linked to the chain via $\mathrm{F}$ bridges [5]. On the other hand, $\mathrm{AgFAsF}_{6}$ dissociates into $\mathrm{AgF}^{+}$and $\mathrm{AsF}_{6}{ }^{-}$in anhydrous $\mathrm{HF}$, resulting in lower oxidizing power than the naked $\mathrm{Ag}^{2+}$ cation [7-10]. Following the oxidation of $\mathrm{As}(\mathrm{III})$ to $\mathrm{As}(\mathrm{V}), \mathrm{AgFAsF}_{6}$ can be easily regenerated using $\mathrm{F}_{2}$ gas at room temperature. Although the oxidation can be performed using other $\mathrm{AgFAF}_{6}$-type compounds (for example, $\left.\mathrm{AgFSbF}_{6}\right), \mathrm{AgFAsF}_{6}$ is preferred because the risk of contamination is lower.

\section{Results and discussion}

\subsection{Preliminary examination}

Table 1 summarizes typical preliminary examination results for the removal of As from HF using $\mathrm{AgFAsF}_{6}$, as well as for methods using distillation, elemental fluorine, and $\mathrm{K}_{2} \mathrm{NiF}_{6}$ which were performed for comparison.

\subsubsection{Distillation}

According to the analysis, the As concentration in the original, distilled, and residual HF samples 
was the same, at $1600 \mathrm{ppm}$ each. The original $\mathrm{HF}$ sample was prepared from $\mathrm{AsF}_{3}$ and $\mathrm{HF}$. The distilled HF sample was produced by distillation into another reactor, and the residual HF sample was that left behind after distillation. If the distillation works, then distillated sample should be poorer in As(III) than original sample, and the residual sample should be richer in As content than original sample. This result means that simple distillation is not effective for reducing the As content in HF.

\subsubsection{Oxidation by elemental fluorine}

The effectivenss of elemental fluorine in removing the As impurity was examined (at room temperature) by introducing $\mathrm{F}_{2}$ in the gas phase over $\mathrm{HF}$ containing $\mathrm{AsF}_{3}$ (eq. 1) and treating with $\mathrm{NaF}$ to completely remove the product $\mathrm{AsF}_{5}$ (eq. 2).

$$
\begin{aligned}
& \mathrm{AsF}_{3}+\mathrm{F}_{2} \rightarrow \mathrm{AsF}_{5} \\
& \mathrm{AsF}_{5}+\mathrm{NaF} \rightarrow \mathrm{NaAsF}_{6}
\end{aligned}
$$

According to the patent covering this process, a small amount of $F_{2}$ gas is quite effective, even within a short period [3]. However, the results of the current study suggest that $\mathrm{F}_{2}$ gas treatment under ambient conditions does not decrease As concentration to the target level (As $<3 \mathrm{ppm}$ ). This is presumably due to the low solubility of $\mathrm{F}_{2}$ gas in HF, although different experimental conditions, such as water impurity and the agitation method used, may have affected the results. 


\subsubsection{Oxidation by $\mathrm{K}_{2} \mathrm{NiF}_{6}$}

Removal of As was also performed via oxidation by $\mathrm{K}_{2} \mathrm{NiF}_{6}$, which is a very strong oxidizer of

$\mathrm{Ni}(\mathrm{IV})[11,12]$. The process is based on the following equation (eq. 3).

$$
\mathrm{AsF}_{3}+\mathrm{K}_{2} \mathrm{NiF}_{6} \rightarrow \mathrm{KAsF}_{6}+\mathrm{NiF}_{2}+\mathrm{KF}
$$

Further treatment to fix $\mathrm{AsF}_{5}$ was not necessary, since it was trapped in the reactor as nonvolatile $\mathrm{KAsF}_{6}$. The final sample was obtained by distilling $\mathrm{HF}$ from the $\mathrm{K}_{2} \mathrm{NiF}_{6}$ reactor to another reactor.

This treatment is effective for reducing the As content from a few hundred ppm to a value below $3 \mathrm{ppm}$. The high solubility of $\mathrm{K}_{2} \mathrm{NiF}_{6}$ in $\mathrm{HF}$ is thought to facilitate the fluorination of $\mathrm{AsF}_{3}$ even under ambient conditions. However, the supply of costly $\mathrm{K}_{2} \mathrm{NiF}_{6}$ is a drawback since the regeneration of the products to $\mathrm{K}_{2} \mathrm{NiF}_{6}$ requires fluorination by elemental fluorine at a high temperature.

\subsubsection{Oxidation by AgFAs $F_{6}$}

The use of $\mathrm{AgFAsF}_{6}$ as an oxidizer to remove As from $\mathrm{HF}$ is based on the following reaction (eq.

4).

$$
\mathrm{AsF}_{3}+2 \mathrm{AgFAsF}_{6} \rightarrow \mathrm{AsF}_{5}+2 \mathrm{AgAsF}_{6}
$$

The reaction proceeds readily since $\mathrm{AgFAsF}_{6}$ has sufficient solubility into $\mathrm{HF}$. In this case treatment with $\mathrm{NaF}$ is necessary for fixing $\mathrm{AsF}_{5}$ (eq. 2). However, the concentration of $\mathrm{AsF}_{5}$ after 
the first cycle was low even before treating with $\mathrm{NaF}$. This is because of the high solubility of $\mathrm{AsF}_{5}$ into the residual $\mathrm{HF}$ in the reactor. Repetitive $\mathrm{AgFAsF}_{6}$ treatments gave increasingly more $\mathrm{AsF}_{5}$ in the distilled HF. After NaF treatment, the final HF had less than 3 ppm of As, compared to a starting concentration of a few hundred ppm. Unlike oxidation by elemental fluorine, this method does not require removal of $\mathrm{F}_{2}$ from the anhydrous HF product and continuous oxidation is possible as long as $\mathrm{AgFAsF}_{6}$ exists in the system.

Since the validity of the $\mathrm{AgFAsF}_{6}$ treatment was confirmed in the preliminary examination, this method was scaled up as shown in the next section.

\subsection{Bench-scale demonstration}

The concept of As removal using $\operatorname{AgFAsF}_{6}$ at an industrial level is shown in Fig. 1. A schematic illustration of the reaction line for the bench-scale demonstration is shown in Fig. 2. A photograph of the PFA (poly(tetrafluoroethylene-co-perfluoro(alkyl vinyl)ether)) reactor used in the bench-scale demonstration can be seen in Fig. S1 (Supplementary material).

The oxidizing reagent $\mathrm{AgFAsF}_{6}$ was prepared from $\mathrm{AgAsF}_{6}$ in $70 \mathrm{~mL}$ of aHF, by fluorination with diluted $\mathrm{F}_{2}$ gas $\left(\mathrm{F}_{2}: \mathrm{N}_{2}=30: 70\right)$, under vigorous agitation in Reactor (B) (eq. 5).

$$
2 \mathrm{AgAsF}_{6}+\mathrm{F}_{2} \rightarrow 2 \mathrm{AgFAsF}_{6}
$$

Diluted $\mathrm{F}_{2}$ gas was used because it is less corrosive than $100 \%$ elemental fluorine, so it is the preferred choice in industrial application. Figure 3 shows the time dependence of the pressure in 
the reactor during fluorination, where the gas phase consists of the diluted $\mathrm{F}_{2} / \mathrm{N}_{2}$ gas and $\mathrm{HF}$ vapor.

The solution began to turn blue within a few minutes of introducing fluorine gas, and the pressure

showed a steep decline during the first twenty minutes. The decrease in pressure ceased within 90

minutes. At this stage, the color of the $\mathrm{HF}$ solution was dark blue. The yield of $\mathrm{AgFAsF}_{6}$, calculated using the uptake of $\mathrm{F}_{2}$ gas and the initial amount of $\mathrm{AgAsF}_{6}$ was $87 \%$. It should be noted that the amount of $\mathrm{F}_{2}$ gas consumed in the first minute of the reaction could not be measured, as the pressure in the reactor had not yet stabilized. The yield can be increased by adding this amount of $\mathrm{F}_{2}$ gas.

In the next step, approximately $430 \mathrm{~mL}$ of a mixture of $\mathrm{HF}$ and $\mathrm{AsF}_{3}$ was prepared in Reactor (A) and transferred into Reactor (B) by distillation. Arsenic trifluoride was oxidized by $\mathrm{AgFAsF}_{6}$ in Reactor (B) and the resulting HF sample was transferred to Reactor (C) by distillation, where $\mathrm{AsF}_{5}$ was trapped by $\mathrm{NaF}$ as $\mathrm{NaAsF}_{6}$. The final $\mathrm{HF}$ was sampled from Reactor $(\mathrm{C})$ by distillation. This $500 \mathrm{~mL}$-scale demonstration successfully reduced the As impurity from a few hundred ppm in the original HF to a concentration below $3 \mathrm{ppm}$. The solution in Reactor (B) became less and less blue as the $\mathrm{AgFAsF}_{6}$ treatment was repeated, and finally became colorless. Regeneration of $\mathrm{AgFAsF}_{6}$ from $\mathrm{AgAsF}_{6}$ was performed in the same manner as its preparation above. In practical processes, accumulating $\mathrm{NaAsF}_{6}$ must be removed from the reactor after a certain number of treatments. If $\mathrm{AgFAsF}_{6}$ regeneration or $\mathrm{NaAsF}_{6}$ removal is time-consuming, a second reactor may need to be installed in parallel to the first. 


\section{Experimental}

\subsection{General experimental procedure}

Moisture-sensitive materials were handled in a glove box under a dry Ar atmosphere. Volatile materials were handled in a reaction line made of stainless steel pipes (SUS-316, 1/2-inch o.d.) which were connected by stainless steel unions and valves with Kel-F tips. The line was connected to a rotary vacuum pump through a soda lime chemical trap, which was connected in series to a liquid nitrogen trap. Occasionally, direct pumping was performed through the liquid nigrogen trap only, in order to obtain a high vacuum $(1<\mathrm{Pa})$. The pressure and vacuum of the line were monitored by Bourdon and Pirani gauges.

\subsection{Reagents}

For bench-scale demostration, anhydrous hydrogen fluoride (Stella Chemifa, purity > $99 \%$ ) was used as supplied, but for the small-scale demonstration it was treated with $\mathrm{K}_{2} \mathrm{NiF}_{6}$ prior to use. Arsenic trifluoride was prepared by reaction of $\mathrm{As}_{2} \mathrm{O}_{3}$ and $\mathrm{HF}$ according to the literature method [13] and stored over $\mathrm{NaF}$. Diluted $\mathrm{F}_{2}$ gas was prepared by mixing $\mathrm{F}_{2}$ (Daikin Industiries) and $\mathrm{N}_{2}$ (extra pure grade, Japan Air Gases) in a ratio of 30 to 70 prior to use.

\subsection{Reactions in the preliminary examination}

Unless otherwise specified, the term "distillation" is taken to mean the transfer of volatile compounds from a reactor at room temperature to another reactor at $-196{ }^{\circ} \mathrm{C}$. An h-shaped PFA 
reactor, equipped with a stainless steel valve at the top and with a PFA valve at the side-arm, was used for the preliminary reactions (Fig. S2 in Supplementary data). The PFA reactor, HF container, and $\mathrm{AsF}_{3}$ container were connected via a three-way PFA connector. To prepare HF with the $\mathrm{AsF}_{3}$ impurity, $\mathrm{AsF}_{3}$ was distilled into the main arm of the h-shaped reactor, and about 4 $\mathrm{mL}$ of $\mathrm{HF}$ was distilled on it. The amount of $\mathrm{AsF}_{3}$ was roughly estimated using the volume of the reaction line, The mixture was then warmed up to room temperature and stirred for a few minutes.

\subsubsection{Removal of As impurity by distillation}

Approximately $4 \mathrm{~mL}$ of $\mathrm{HF}$ with $\mathrm{AsF}_{3}$ impurity was prepared in the main arm of an h-shaped reactor, using the method described in section 3.3. Half of the sample was poured into the side arm and the PFA valve was closed. The other half in the main arm was distilled onto $\sim 4 \mathrm{~mL}$ of frozen $\mathrm{H}_{2} \mathrm{O}$ to give Sample D-1. Half of the mixture in the side arm was distilled onto $\sim 4 \mathrm{~mL}$ of frozen $\mathrm{H}_{2} \mathrm{O}$ in another PFA reactor and collected as Sample D-2 and the remainder was distilled onto $\sim 4 \mathrm{~mL}$ of frozen $\mathrm{H}_{2} \mathrm{O}$ in one more PFA reactor (Sample D-3). These samples provide the As content in three states: the original HF (Sample D-1), the distilled HF (Sample D-2), and the residual HF (Sample D-3), as shown in Table 1.

\subsubsection{Removal of As impurity using elemental fluorine}

Approximately $4 \mathrm{~mL}$ of $\mathrm{HF}$ with $\mathrm{AsF}_{3}$ impurity was prepared in the main arm of an h-shaped reactor, using the same method described in section 3.3. Half of the HF sample was poured into 
the side arm, and the PFA valve was closed. The other half was distilled onto $\sim 4 \mathrm{~mL}$ of frozen $\mathrm{H}_{2} \mathrm{O}$ in another PFA reactor (Sample F-1). The contents of the side tube were then distilled into a separate PFA reactor ( $\sim 80 \mathrm{~mL}$ in volume) equipped with a stainless steel valve. Approximately 0.4 atm of $F_{2}$ gas was introduced into the gas phase at room temperature, followed by vigorous agitation for 40 minutes. The fluorine gas was pumped off under vacuuum at $-85^{\circ} \mathrm{C}$ for a few minutes, and the HF sample was distilled into a PFA reactor containing $100 \mathrm{mg}$ of $\mathrm{NaF}$. The solution was warmed up to room temperature and stirred for five minutes, during which time the $\mathrm{NaF}$ completely. Most of the resulting $\mathrm{HF}$ was distilled onto $\sim 4 \mathrm{~mL}$ of frozen $\mathrm{H}_{2} \mathrm{O}$ in another PFA reactor to give Sample F-2. Complete transfer of HF was difficult at this stage, due to the strong HF-absoption ability of $\mathrm{NaF}$ (forming $\mathrm{Na}(\mathrm{FH})_{n} \mathrm{~F}[14,15]$ ). Sample F-1 provided the As content of the original HF, and Sample F-2 provided that of the HF treated with $F_{2}$ as shown in Table 1.

\subsubsection{Removal of As impurity using $\mathrm{K}_{2} \mathrm{NiF}_{6}$}

Approximately $4 \mathrm{~mL}$ of $\mathrm{HF}$ containing $\mathrm{AsF}_{3}$ impurity was prepared as described in 3.3 . Half of the HF sample was poured into the side arm of the h-shaped tube and the PFA valve was closed. The HF in the main tube was distilled onto $\sim 4 \mathrm{~mL}$ of frozen $\mathrm{H}_{2} \mathrm{O}$ in a PFA reactor (Sample Ni-1). The contents of the side tube were then distilled onto $\mathrm{K}_{2} \mathrm{NiF}_{6}(128 \mathrm{mg})$ in a PFA reactor equipped with a stainless steel valve. A red-purple $\mathrm{HF}$ solution of $\mathrm{K}_{2} \mathrm{NiF}_{6}$, obtained by warming up the mixture to room temperature, was stirred for five minutes. Most of the resulting HF sample was 
distilled onto $\sim 4 \mathrm{~mL}$ of frozen $\mathrm{H}_{2} \mathrm{O}$ in another PFA reactor to give Sample Ni-2. The As content of the original HF (Sample Ni-1) and the $\mathrm{K}_{2} \mathrm{NiF}_{6}$-treated HF (Sample Ni-2) were obtained, as shown in Table 1.

\subsubsection{Removal of As impurity using AgFAsF 6}

Approximately $4 \mathrm{~mL}$ of $\mathrm{HF}$ with $\mathrm{AsF}_{3}$ impurity was prepared as described in section 3.3. Half of the HF sample was poured into the side arm of the h-shaped tube and the PFA valve was closed.

The HF in the main tube was distilled onto $\sim 4 \mathrm{~mL}$ of frozen $\mathrm{H}_{2} \mathrm{O}$ in another PFA reactor (Sample Ag-1). The contents of the side arm were distilled onto $\operatorname{AgFAsF}_{6}(100 \mathrm{mg}$ ) in a PFA reactor equipped with a stainless steel valve. A blue solution, obtained by warming up to room temperature, was stirred for five minutes. This sample was distilled onto $100 \mathrm{mg}$ of $\mathrm{NaF}$ in another PFA reactor, warmed up to room temperature, and stirred for five minutes to give Sample Ag-2. These samples provide the As content of the original (Sample Ag-1) and AgFAsF -treated $_{6}$ HF (Sample Ag-2).

\subsection{Reactions in the bench-scale demonstration}

\subsubsection{Preparation and regeneration of $A g F A s F_{6}$ in the bench-scale demonstration}

The starting compound $\mathrm{AgAsF}_{6}(8.222 \mathrm{~g}, 0.02867 \mathrm{~mol})$ was loaded in a PFA reactor $(\sim 1 \mathrm{~L}$ in volume, Fig. S1) under a dry Ar atmosphere, and the reactor was connected to the reaction line 
(Fig. 2) as Reactor (B). Approximately $70 \mathrm{~mL}$ of anhydrous $\mathrm{HF}$ was distilled onto the $\mathrm{AgAsF}_{6}$ in

Reactor (B) from a storage vessel. Tanks (A) and (B), each containing $1 \mathrm{~L}$ of diluted $\mathrm{F}_{2}$ gas $\left(\mathrm{F}_{2}\right.$ : $\mathrm{N}_{2}=30: 70$ ), were connected to the reaction line. The gas in Tank (A) was introduced to Reactor (B) and the valve of Tank (A) was closed once pressure equilibrated. The gas in Tank (B) was also introduced to Reactor (B), but its valve was kept open during the reaction. This led to a volume of 2.1 L for the gas phase contained in Reactor (B), Tank (B), and the connecting portion. The HF solution was vigorously agitated during the reaction, and the end point was confirmed by a change in color and pressure.

\subsubsection{Oxidation of $A s F_{3}$ in the bench-scale demonstration}

Approximately $430 \mathrm{~mL}$ of $\mathrm{HF}$ was condensed from a storage cylinder to Reactor (A) at $-90{ }^{\circ} \mathrm{C}$.

Reactor (B) contained $\mathrm{AgFAsF}_{6}$, prepared as described in sub-section 3.4.1, and Reactor (C) contained $\mathrm{NaF}$ (2.2 g, $0.05 \mathrm{~mol})$. An amount of $\mathrm{AsF}_{3}$ esitmated from the volume of the reaction line was condensed onto the $\mathrm{HF}$ in Reactor (A) at $-90^{\circ} \mathrm{C}$. The mixture was warmed up to room temperature and stirred for five minutes. Approximately $4 \mathrm{~mL}$ of the $\mathrm{HF}$ in Reactor (A) was distilled onto $\sim 4 \mathrm{~mL}$ of frozen $\mathrm{H}_{2} \mathrm{O}$ in a PFA tube (Sample Bench-1). The rest was distilled onto $70 \mathrm{~mL}$ of $\mathrm{HF}$ in Reactor (B) at $-90{ }^{\circ} \mathrm{C}$. The solution was warmed up to room temperature, stirred for five minutes, and distilled into Reactor (C), where $\mathrm{AsF}_{5}$ was trapped by $\mathrm{NaF}$ as $\mathrm{NaAsF}_{6}$. 
Approximately $4 \mathrm{~mL}$ of the final $\mathrm{HF}$ in Reactor (C) was distilled onto $\sim 4 \mathrm{~mL}$ of frozen $\mathrm{H}_{2} \mathrm{O}$ in another PFA tube (Sample Bench-2).

\subsection{Analysis}

The HF sample distilled onto $\mathrm{H}_{2} \mathrm{O}$ in a PFA reactor for all the treatments above was diluted with more $\mathrm{H}_{2} \mathrm{O}$, and sent for analysis as $3 \sim 10 \%$ hydrofluoric acid. The concentration of As in the sample was measured by ICP-AES (SPS3000, Seiko Instruments Inc.), and the concentration of HF was measured by titration.

\section{Acknowledgements}

This research was performed in collaboration with Todai TLO, Ltd. and was financially supported by New Energy and Industrial Technology Development Organization (NEDO). The authors gratefully acknowledge the advice of Mr. Takuya Arase and Mr. Takashi Kanemura of Daikin Industries Ltd., Mr. Kazuya Oharu and Mr. Tsutomu Naganuma of Asahi Glass Co. Ltd., and Mr. Hiromitsu Takeyasu of Japan Chemical Innovation Institute (JCII).

\section{Appendix A. Supplementary data}

Supplementary data associated with this article can be found, in the online version, at doi:10.1016/j.jfluchem.2010.04.006. 


\section{References}

[1] H. Russell, R. E. Rundle, D. M. Yost, J. Am. Chem. Soc. 63 (1941) 2825.

[2] J. Simons, J. Am. Chem. Soc. 46 (1924) 2179.

[3] For example: Japanese patents 16407 (1972), 151002 (1986), 502277 (1990), 146401 (1991), 205304 (1991), 263406 (1994), and 504149 (1995), US patents 4032621 (1977), 4083941 (1978), 4424067 (1984), 4491570 (1985), 4668497 (1987), 4756899 (1988), 4,960,580 (1990), 4,954,330 (1990), 4990320 (1991), 5,108,559 (1992), 5,100,639 (1992).

[4] B. Frlec, D. Gantar, J. H. Holloway, J. Fluorine Chem. 20 (1982) 385.

[5] D. Gantar, B. Frlec, D. R. Russell, J. H. Holloway, Acta Cryst. C43 (1987) 618.

[6] W. Grochala, R. Hoffmann, Angew. Chem. Int. Ed. 40 (2001) 2742.

[7] B. Žemva, R. Hagiwara, W. J. Casteel, K. Lutar, A. Jesih, N. Bartlett, J. Am. Chem. Soc. 112 (1990) 4846.

[8] N. Bartlett, G. Lucier, C. Shen, W. J. Casteel, L. Chacon, J. Munzenberg, B. Žemva, J. Fluorine Chem. 71 (1995) 163.

[9] G. Lucier, C. Shen, W. J. Casteel, L. Chacón, N. Bartlett, J. Fluorine Chem. 72 (1995) 157.

[10] B. Žemva, K. Lutar, A. Jesih, W. J. Casteel, A. P. Wilkinson, D. E. Cox, R. B. Von Dreele, H. Borrmann, N. Bartlett, J. Am. Chem. Soc. 113 (1991) 4192.

[11] L. Stein, J. M. Neil, G. R. Alms, Inorg. Chem. 8 (1969) 2472.

[12] B. Žemva, K. Lutar, L. Chacón, M. Fele-Beuermann, J. Allman, C. Shen, N. Bartlett, J. Am. 
Chem. Soc. 117 (1995) 10025.

[13] G. Brauer (ed.), Handbuch der Präparativen Anorganischen Chemie, Ferdinand Enke Verlag, Stuttgart (1954).

[14] R. L. Adamczak, J. A. Mattern, H. Tieckelmann, J. Phys. Chem. 63 (1959) 2063.

[15] G. A. Bottomley, J. B. Farrow, F. J. Lincoln, Aust. J. Chem. 36 (1983) 649. 
Table 1 Summary of As removal results in preliminary examination ${ }^{a}$

\begin{tabular}{lllll}
\hline & \multicolumn{2}{l}{$\begin{array}{l}\text { As content before treatment } \\
\text { / ppm }\end{array}$} & $\begin{array}{l}\text { As content after treatment } \\
\text { / ppm }\end{array}$ \\
\hline Distillation $^{b}$ & $(\mathrm{D}-1)$ & 1600 & $(\mathrm{D}-2)$ & 1600 \\
Elemental fluorine & $(\mathrm{F}-1)$ & 1600 & $(\mathrm{~F}-2)$ & 18 \\
$\mathrm{AgFAsF}_{6}$ & $(\mathrm{Ag}-1)$ & 489 & $(\mathrm{Ag}-2)$ & $<3$ \\
$\mathrm{~K}_{2} \mathrm{NiF}_{6}$ & $(\mathrm{Ni}-1)$ & 464 & $(\mathrm{Ni}-2)$ & $<3$ \\
\hline${ }^{a}$ The symbol of each result such as (D-1) refers to the sample name in Experimental $^{2}$ & \\
section. ${ }^{b}$ The As content in the residual HF sample (D-3) was also 1600 ppm. \\
\hline
\end{tabular}




\section{Figure captions}

Fig. 1 Concept of the removal of As using $\mathrm{AgFAsF}_{6}$.

Fig. 2 Schematic illustration of the reaction line used in the bench-scale demonstration.

Fig. 3 Time dependence of the pressure in the reactor during fluorination of $\mathrm{AgAsF}_{6}$ by $\mathrm{F}_{2}$ gas in the bench-scale demonstration. 


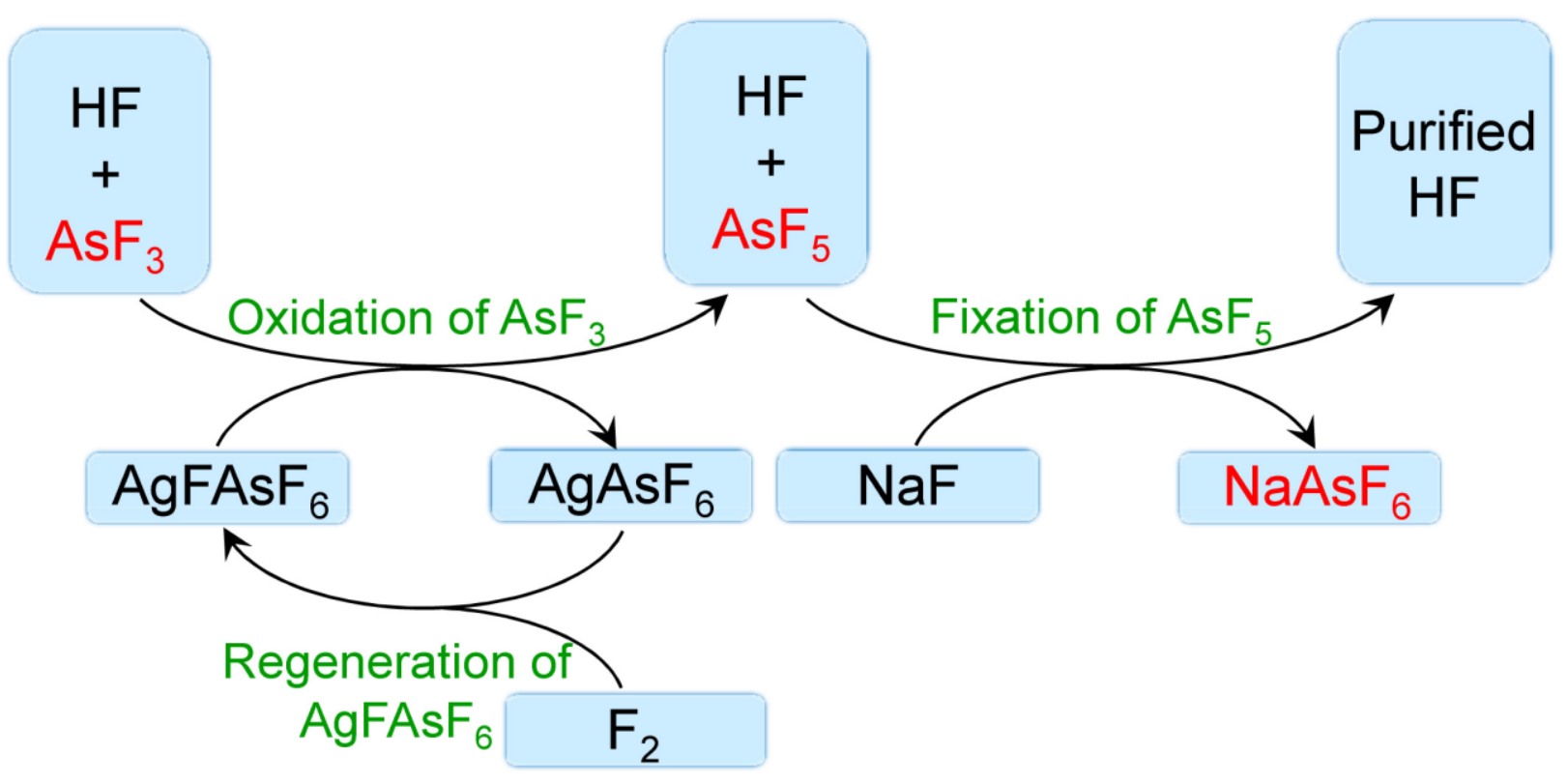

Fig. 1 Concept of the removal of As using $\mathrm{AgFAsF}_{6}$. 


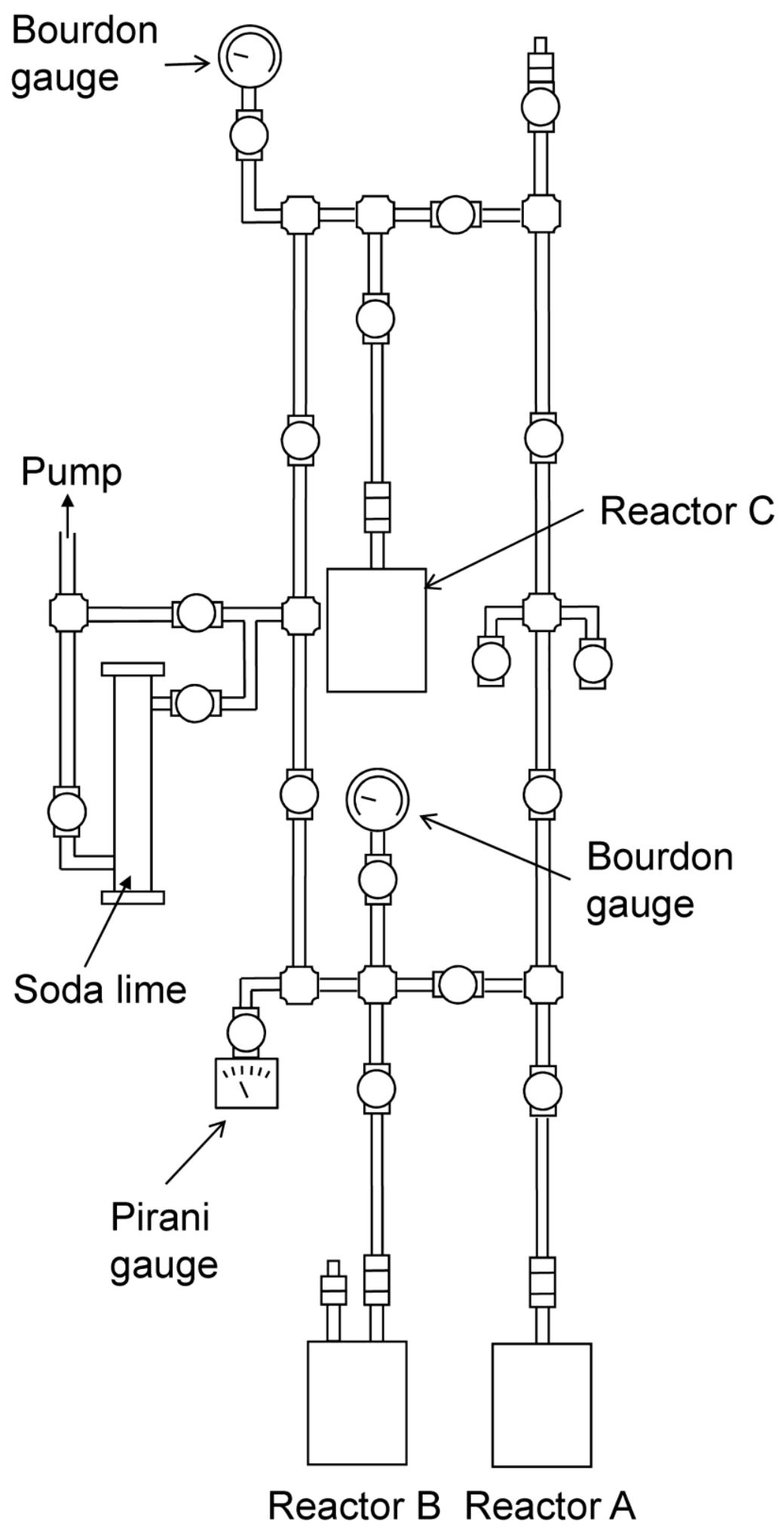

Fig. 2 Schematic illustration of the reaction line used in the bench-scale demonstration. 


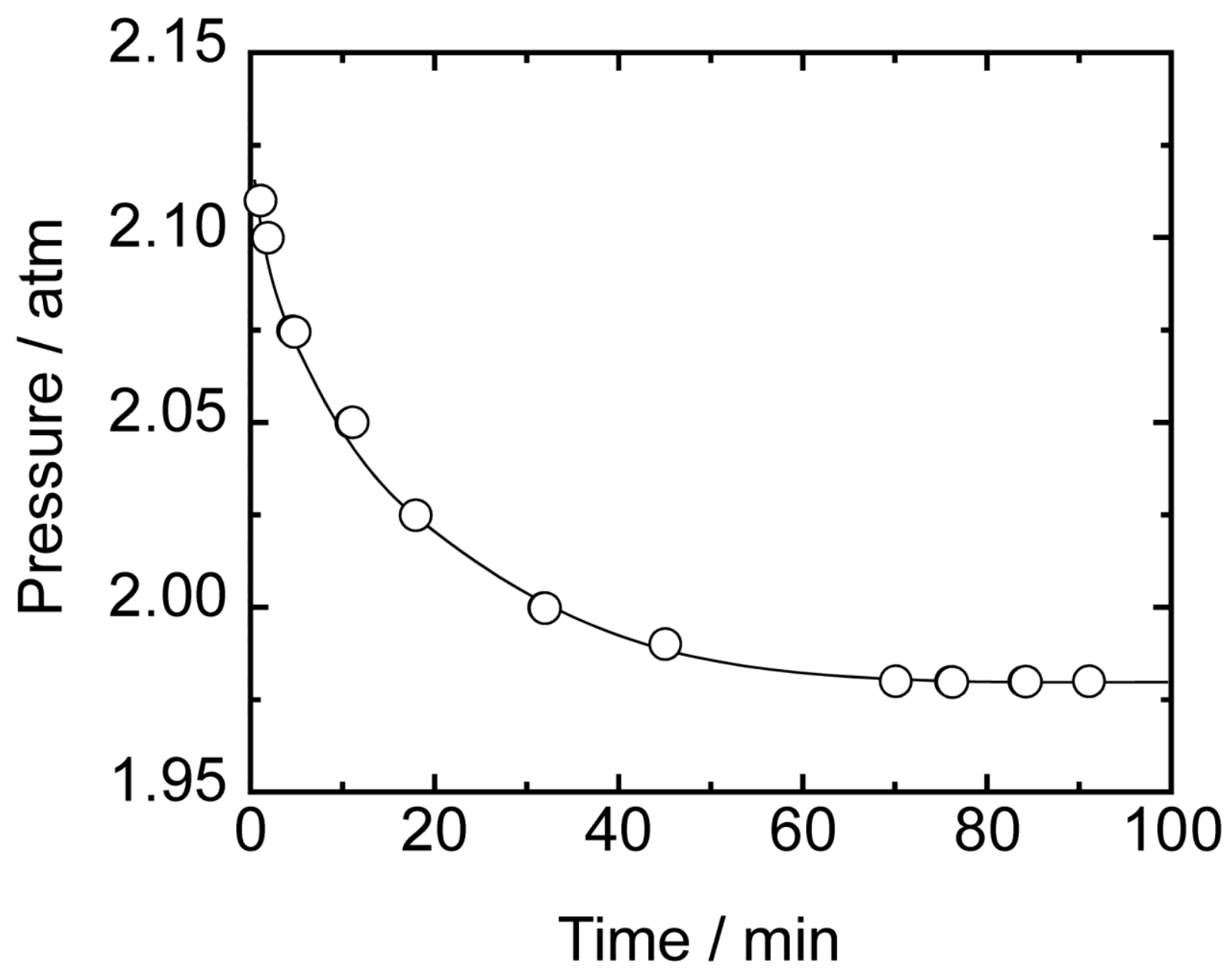

Fig. 3 Time dependence of the pressure in the reactor during fluorination of $\mathrm{AgAsF}_{6}$ by $\mathrm{F}_{2}$ gas in the bench-scale demonstration. 


\section{Supplementary Contents}

Elimination of $\mathrm{AsF}_{3}$ from anhydrous HF by using $\mathrm{AgFAsF}_{6}$ as a mediator ${ }^{\dagger}$

Kazuhiko Matsumoto*, Rika Hagiwara

Graduate School of Energy Science, Kyoto University, Sakyo-ku, Kyoto 606-8501, Japan,

*E-mail: k.matsumoto@ky7.ecs.kyoto-u.ac.jp

Tel: $+81-75-753-5822$

Fax: +81-75-753-5906 

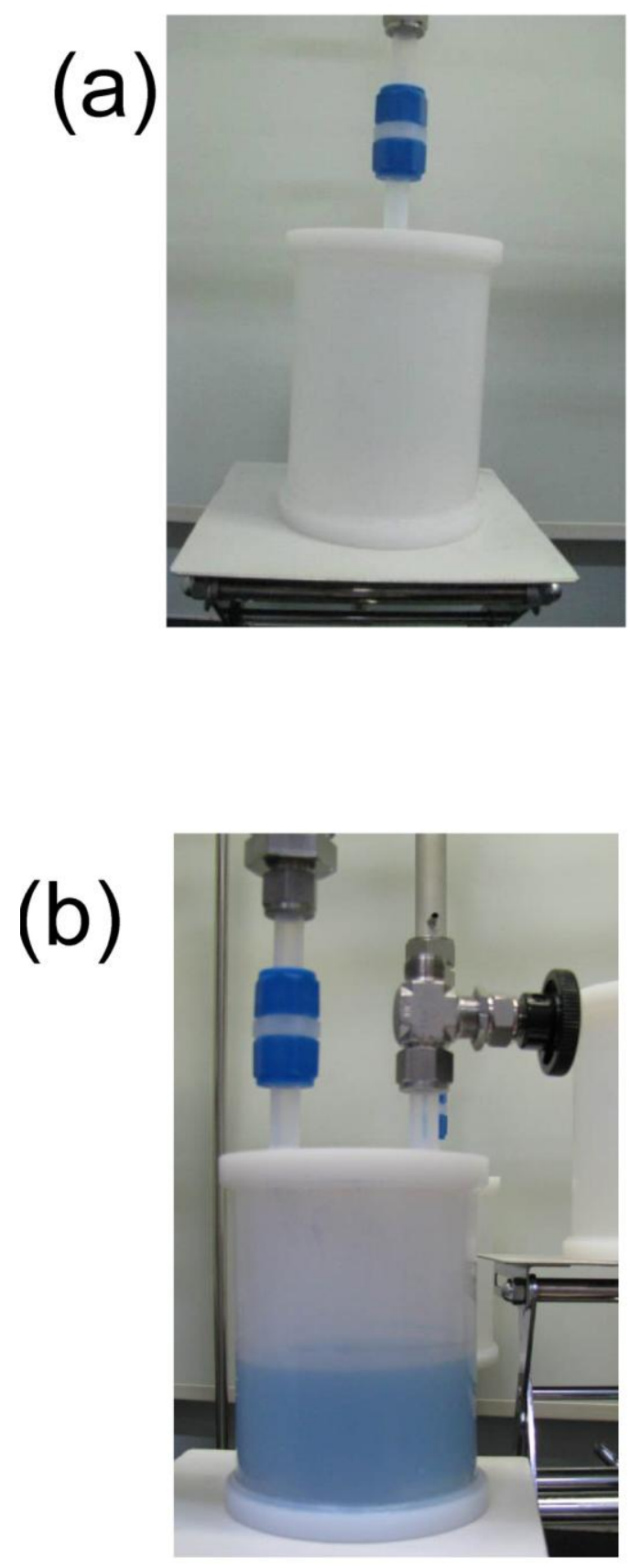

Fig. S1 Photographs of PFA reactors for (a) Reactor A or C and (b) Reactor B in Fig. 2. The reactor in the photograph (b) contains $\sim 500 \mathrm{~mL}$ of $\mathrm{HF}$ with $\mathrm{AgFAsF}_{6}$. 


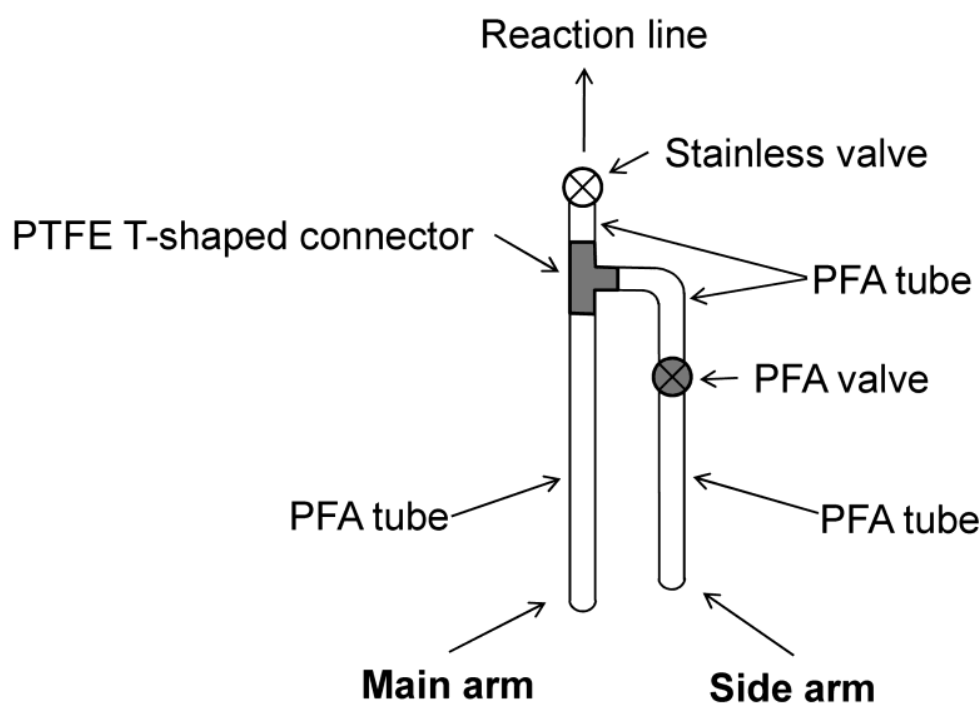

Fig. S2 An h-shaped PFA reactor used for preliminary examination. 